\title{
O doce veneno da cultura de massa ou o que Bruna Surfistinha tem a nos ensinar para além do Kama Sutra pop
}

\author{
Maurício de Bragança \\ Universidade Federal Fluminense (Niterói, Brasil)
}

RESUMO: EM 2005, O MERCADO BRASILEIRO RECEBEU UM FENÔMENO EDITORIAL: O DOCE VENENO DO ESCORPIÃO, DE BRUNA SURFISTINHA. AQUI PRETENDEMOS DISCUTIR OS LIMITES DO TEXTO LITERÁRIO A PARTIR DA SUAS RELAÇÕES COM O MERCADO. O DESPRESTÍGIO DESTAS NARRATIVAS LITERÁRIAS INDICA UM INCÔMODO HISTÓRICO QUE MARCA A RELAÇÃO ENTRE A CRÍTICA E O LEITOR DESTES TEXTOS MASSIVOS. TAIS RELAÇÕES, PORÉM, NOS AJUDAM A COMPREENDER AS QUESTÕES REFERENTES AO ÂMBITO DA INTERIORIDADE E DA EXPOSIÇÃO MIDIÁTICA MARCADAS PELA DIMENSÃO ESPETACULAR PRESENTE NA SOCIEDADE CONTEMPORÂNEA.

ABSTRACT: IN 2005, THE BRAZILIAN MARKET HAS RECEIVED A PUBLISHING PHENOMENON: O DOCE VENENO DO ESCORPIÃO, WRITTEN BY BRUNA SURFISTINHA. IN THIS ARTICLE WE INTEND TO DISCUSS THE LIMITS OF THE LITERARY TEXT FROM ITS RELATIONS WITH THE MARKET. THE LACK OF PRESTIGE OF THESE LITERARY NARRATIVES INDICATES AN UNCOMFORTABLE HISTORY THAT MARKS THE RELATIONSHIP BETWEEN CRITICISM AND THE READER OF THESE TEXTS. SUCH RELATIONSHIPS, HOWEVER, INDICATE THE ISSUES REGARDING THE SCOPE OF INTERIORITY AND MEDIA EXPOSURE MARKED BY SPECTACULAR DIMENSION PRESENT IN CONTEMPORARY SOCIETY.

PALAVRAS-CHAVE: LITERATURA, MERCADO, CULTURA DE MASSA.

KEYWORDS: LITERATURE, MARKET, MASSIVE CULTURE. 
este artigo pretendemos discutir os limites do texto literário a partir da suas relações com o mercado. Esta relação sempre se estabelece de forma tensa, já que aos olhos de uma crítica constituída por critérios tradicionais de valor artístico, o mercado parece forjar uma relação espúria com o fazer literário, corrompendo seu potencial enquanto arte. A falta de prestígio presente na recepção crítica destas narrativas literárias, decorrente da circulação desta produção por um mercado focado, geralmente, na lista dos best-sellers, indica um histórico incômodo que atravessa a relação entre a crítica e o leitor destes textos de caráter mais massivo.

As históricas relações entre literatura e suas vertentes mercadológicas de apropriação nos remetem a um gênero literário e a uma forma de publicação que se constituiu ainda na primeira metade do século XIX. O modelo desprestigiado do folhetim surgiu atravessado por uma relação direta com o leitor, marcado pela perspectiva de circulação no mercado. Isso conferia ao romance-folhetim um caráter diferenciado na própria criação do texto, afetado por mecanismos de aferição do gosto do público, o que contribuía com novas formas narrativas e, inclusive, novas reflexões sobre criação e autoria. Em meados do século XIX, escritores, que pela tradição da historiografia literária viriam a constituir cânones da literatura ocidental, publicavam suas obras de forma serializada nas páginas de jornais.

O primeiro romance a ser publicado "em pedaços" foi Lazarillo de Tormes, em 1836, e já neste mesmo ano Balzac aceitou uma encomenda de folhetim. Assim foi o surgimento do romance-folhetim que rapidamente ganhou espaço no cenário literário do século XIX, adotando algumas características particulares fundamentais ao novo gênero destinado a um público de massa: o desenvolvimento de uma técnica de corte na narrativa a fim de manter o suspense até o número seguinte, sem alterar, porém a ideia de continuidade da mesma; e uma estrutura que simplificava a caracterização das personagens com fórmulas maniqueístas de ritmo acelerado, abarcando um universo romântico inserido nos códigos dos mitos modernos da grande cidade (MEYER, 1996).

O sensacionalismo e a serialização, característicos deste tipo de narrativa, tanto no estilo quanto na estrutura, apontavam para o surgimento de uma nova sensibilidade tipicamente moderna, a partir da qual os modos de percepção e de subjetivação se alteraram em função da experiência do desenvolvimento tecnológico e dos novos fluxos impostos pela vida na cidade. 
Segundo Ben Singer (2001), a cidade moderna promoveu o desenvolvimento de hiperestímulos decorrentes de novos critérios de tempo e espacialidade que afetavam a percepção de ordem visual e auditiva numa carga de ansiedade proveniente de atos reflexos e impulsos nervosos. Os acontecimentos urbanos, decorrentes desta nova subjetividade vivida a partir de uma nova relação com o tempo e com o espaço, traziam consigo um sentimento de insegurança e vulnerabilidade jamais experimentado anteriormente ou, ao menos, de uma forma extremamente diferente. A cidade moderna parecia ameaçadora na sua produção de hiperestímulos relacionados ao medo e à violência. É neste contexto que surge uma cultura do sensacionalismo destinada ao consumo em massa relacionada não somente a uma "simples manifestação da curiosidade mórbida e oportunismo econômico, mas também a uma hiperconsciência especificamente histórica da vulnerabilidade física no ambiente moderno" (SINGER, 2001, p. 127).

Num mundo afetado pelas novas demandas dos influxos industriais, a serialização narrativa refletia também a própria experiência de fragmentação produzida, tanto na natureza do novo modelo de produção industrial, que abandonava o conhecimento integral dos processos de produção em função da segmentação do trabalho, quanto na própria fragmentação do conhecimento, uma nova formulação do pensamento e da experiência de subjetividade.

A importância que o folhetim assumiu no jornal foi impressionante: "a partir de então, não se trata mais, para o romance-folhetim, de trazer ao jornal o prestígio da ficção em troca da força de penetração deste, mas, pelo contrário, é o romance que vai devorar seu veículo" (MEYER, 1996, p. 61). Deste modo, o folhetim definiu na segunda metade do século XIX a forma de publicação do romance.

A década de 1840 marca a definitiva constituição do romance-folhetim como gênero específico de romance. Eugène Sue publica no Journal des Débats entre 1842 e 1843 Os mistérios de Paris. Em 1844 sai, do mesmo Sue, O judeu errante; de Dumas, Os três mosqueteiros e $O$ conde de Monte Cristo; de Balzac, a continuação folhetinesca de As ilusões perdidas, ou seja, Esplendores e misérias das cortesãs. A invenção de Dumas e Sue vai se transformar numa receita de cozinha reproduzida por centenas de autores. A fórmula tem outra consequência: uma nova formulação do termo folhetim, que passa então a designar também o que se 
torna o novo modo de publicação de romance. Praticamente toda a ficção em prosa da época passa a ser publicada em folhetim, para então depois, conforme o sucesso obtido, sair em volume (MEYER, 1996, p. 63).

Perceba-se que, na análise de Meyer, a publicação em volume do romance, naquela época, dependia praticamente da aceitação do público, do sucesso que essas narrativas faziam em sua recepção no mercado de leitores dos jornais. Esse consumo rápido de recepção imediata orientava a formação do mercado editorial. O público leitor/consumidor, aliás, assumiu um local de destaque nesta dinâmica onde lhe coube, inclusive, o papel de comentarista da trama que acompanhava, dando sugestões para o desenvolvimento da história que se configurava como uma obra aberta, e interferindo na condução dos destinos das personagens. Era o surgimento da ideia de interação nos meios de comunicação, com a criação da coluna de cartas dos leitores. Ao escritor cabia ouvir este leitor opinativo, que muitas vezes conduzia a trama do exotismo à realidade. Neste movimento, o autor acabava por inserir na trama apelos imediatos ao mundo real. "Coloca-se para o autor uma certa necessidade na elaboração do romance que vai tecendo, impelido por vastas e imprevistas determinações. Agradar ao público continua, evidentemente, sendo uma delas. Mas agradar aceitando sua colaboração, seguindo suas sugestões, que chegam por via de cartas" (MEYER, 1996, p. 76). Esta participação do leitor aferia a popularidade e o êxito comercial da obra, que tinha reflexos diretos na venda dos jornais. Meyer (1996) afirma que a popularidade de determinadas personagens determinava o surgimento de romances seriados, nos quais a personagem principal de um romance de sucesso voltava em uma nova aventura a ser seguida pelo público. O romancista assumia um papel definido de fabricante de um produto destinado a um mercado de consumo em larga escala.

Assim, a despeito das particularidades narrativas e da maneira como tal modelo construía sua inserção no mercado e na crítica, a literatura apresentava sua própria história com a indústria alicerçada num circuito midiático instaurado pelo mercado que contribuiu para relações específicas com um público receptor.

Atualmente, muitas destas narrativas encontram seus leitores através de outros suportes, como é o caso da literatura de blogs que cresce constantemente na internet, ampliando seu público. Este apresenta algumas semelhanças 
com aquele leitor participativo e opinativo da literatura em folhetim. O blog, porém, não deve ser encarado apenas como um outro suporte para o texto, já que este tipo de escritura, como o foi o romance-folhetim à sua época, estabelece outros padrões de relação leitor/texto/autor, e também aponta para o surgimento de um novo modelo de subjetividade, atravessada pelas novas tecnologias e por uma nova dimensão da experiência da interioridade, o que se reflete em novas práticas de leitura.

Assim como o romance-folhetim sugeria uma nova sensibilidade marcada pelo novo cenário tecnológico que surgia com a cidade do século XIX na sua relação com as políticas do mercado editorial, os textos presentes nos blogs contemporâneos também têm muito a dizer sobre uma outra sensibilidade que também responde aos novos influxos tecnológicos e na sua inserção em outras políticas editoriais de mercado. Sobre as relações entre subjetividade e tecnologia que marcam as narrativas autobiográficas dos blogs, Paula Sibilia (2008) reforça a ideia de uma "intimidade inventada" como espetáculo das mídias interativas.

Num panorama em que as celebridades se sucedem incessantemente, convidando os espectadores a participarem de sua "intimidade", o blog parece funcionar como uma janela aberta aos leitores que acompanham as narrativas serializadas. Muitos "blogueiros", devido ao sucesso que atingem junto a seus públicos, acabam tendo a chance de publicar os textos postados em livros.

Em 2005, a editora Panda Books lançou no mercado brasileiro um livro que se tornaria um fenômeno com mais de 250 mil exemplares vendidos: $O$ doce veneno do escorpião, que levava ainda o subtítulo "o diário de uma garota de programa". No romance de tom autobiográfico, escrito com a ajuda de um ghost writer, Jorge Tarquini, eram relatadas as experiências de uma garota de programa de classe média de São Paulo que, algum tempo antes, havia decidido dividir suas histórias num blog que chegou a contar, naquela época, com mais de 10 mil visitas mensais. Bruna Surfistinha, a garota de programa brasileira que resolvera abrir sua intimidade para o público internauta, não estava sozinha nessa empreitada. Blogs de prostitutas haviam se tornado relativamente comuns em outros cantos do planeta quando a nossa conectada garota de programa expunha seu dia a dia como trabalhadora do sexo na internet.

Belle de Jour era uma garota de programa inglesa que, durante os anos de 2003 e 2004, resolveu publicar seus diários num blog anônimo intitulado Belle 
de Jour: diary of a London call girl. Seus relatos tornaram-se rapidamente populares, instigando milhares de internautas, atiçados também em torno das especulações sobre a identidade da despudorada escritora. Ainda de forma anônima, suas experiências sexuais foram publicadas em dois volumes: The intimate adventures of a London call girl, de 2005, e The further adventures of a London call girl, de 2006. Estes livros logo chegariam à lista dos dez mais vendidos na Grã-Bretanha, o que impulsionaria estas narrativas para outras mídias, através da adaptação de suas histórias para uma série de TV intitulada Secret diary of a call girl. Assim, a circulação intermidiática pelo mercado proporcionava uma sobrevida aos tórridos relatos sexuais de Belle de Jour. ${ }^{1}$

Em 2005, a portuguesa Maria Porto, pseudônimo utilizado por Andreia Vilhena, também começou a narrar suas práticas como garota de programa num blog intitulado A tua amiga. Em janeiro de 2007, o livro que trazia os relatos postados no blog foi lançado com o mesmo título. Na contracapa, vinha o seguinte texto:

É isso mesmo: o relato dos bizarros episódios que marcam o dia-a-dia de uma acompanhante, num registo tão mordaz e hilariante que atinge foros de crueldade. Aqui não há lugar para a ficção... Com brutal frontalidade, Maria Porto dá a cara e devolve-nos um retrato do monstro ou do vulcão que podemos encontrar dentro de cada um de nós; sem meias palavras. Mais hardcore que este livro, nem os canais eróticos da Pay-Tv... Quem leu O Meu Pipi passará a considerá-lo, depois de ler A Tua Amiga, um inocente manual de escoteiros. Para os mais sensíveis fica o aviso: este livro pode conter linguagem e cenas eventualmente chocantes. ${ }^{2}$

É interessante o registro documental que os relatos de Maria Porto parecem querer evocar, reforçado aqui nas palavras do autor do texto de apresentação do livro. Mas será que estes limites entre o documental e o ficcional podem ser tão bem demarcados? A própria escrita sob pseudônimo não apontaria, a partir da instabilidade da figura do autor centrado, alguma espécie de autofa-

1. Há dois anos, o jornal britânico The Sunday Times revelou a identidade da famosa garota de programa. Tratava-se de Brooke Magnanti, médica pesquisadora da Universidade de Bristol que assumiu a profissão durante a época que fazia seu doutorado como forma de custear seus estudos.

2. Disponível em: <http://atuaamiga.blogs.sapo.pt/68463.html>. 
bulação? Ora, a literatura está repleta de personagens de prostitutas de todos os tempos e de todas as nacionalidades, e seguramente poderíamos incluir Maria Porto ou Bruna Surfistinha no seleto grupo de personagens de que fazem parte Nana, Geni, Lúcia/Maria da Glória, Tieta, Marguerite Gautier, Madame Clessi, Hilda Furacão, Santa, Pombinha, dentre muitas outras mais. ${ }^{3}$

A literatura de tema prostibular, ou que aborda as mazelas e desafios das mulheres de vida dita fácil, é tão antiga quanto o próprio ofício que exercem nas narrativas. Mas aqui, diferentemente das suas companheiras de ofício literário, temos uma personagem que narra a si mesma. Ou não. $O$ doce veneno do escorpião é assinado por Bruna Surfistinha, nome de guerra de Raquel Pacheco que, a partir dos seus relatos postados no blog, deu seu depoimento de vida, ou dos três anos em que ganhou dinheiro como trabalhadora do sexo, a um ghost writer. Na trama, a protagonista constrói-se através de uma autofabulação por meio da exposição de sua "intimidade", ou, como prefere conceituar Paula Sibilia em tempos de autofabulação espetacularizada e midiática, sua "extimidade". Neste ponto, começamos a relativizar não apenas as fronteiras do que se convencionou chamar de literatura (o texto escrito numa linguagem específica para ser acessado na tela de um computador), mas também podemos proceder a um questionamento sobre os limites entre o testemunhal e a autofabulação num texto autobiográfico de natureza como a de Bruna Surfistinha.

É interessante que nesta primeira incursão da autora ao mercado editorial, seu texto seja assinado pela personagem criada para atender aos prazeres e desejos dos seus clientes (e aos seus próprios como é diversas vezes afirmado nos relatos das várias experiências sexuais presentes no livro). No segundo livro, lançado em 2006, O que aprendi com Bruna Surfistinha, quem assina o texto é Raquel Pacheco, assim como no terceiro, Na cama com Bruna Surfistinha, de 2007. Pelos títulos, a autora parece fazer uma clara distinção entre autora e personagem e, embora assuma as picantes histórias que narra em seu livro de estreia, não deixa de enfatizar um afastamento entre Raquel e Bruna.

3. Não por acaso, num relato de seu blog, postado em 21 de março de 2011, Bruna Surfistinha, ao contar como foi a tarde de autógrafos de relançamento de seu livro em Ribeirão Preto, cita um senhor que lhe deu de presente o romance Tereza Batista cansada de guerra, de Jorge Amado. Disponível em: < http:/ / naonaopara.virgula.uol.com.br/brunasurfistinha/ evento-na-livraria-da-vila/>. 
É estranho imaginar que um monte de gente sabe da sua vida, como se estivessem invadindo minha casa e revirando as gavetas. Ao mesmo tempo, descobri que era isso exatamente o que eu queria: que as pessoas lessem sobre a minha vida. Ao menos sobre a pública. Não a da Raquel, mas a da Bruna Surfistinha (SURFISTINHA, 2005, p. 89-90).

Parece estranha, e talvez anacrônica, a distinção que Pacheco estabelece sobre a personagem "pública" de Bruna Surfistinha. Ela mesma parece confusa sobre os limites da vida entre uma e outra, sobre os limites da intimidade e o espaço da exterioridade, sobre a privacidade dos encontros sexuais da garota de programa e a visibilidade destas narrativas proporcionadas pela escrita no blog. Através de um relato que se configura entre as fronteiras da ficção, da arte e documento (o registro depoimental), as narrativas dos blogs não deixam de impor um diálogo com a tradição da autobiografia, dando relevo a uma discussão sobre a performance de si no espetáculo público do exercício da intimidade. Nessa chave, Paula Sibilia desvela uma lógica que parece alicerçar tais narrativas a partir daquilo que Guy Debord denominou "a sociedade do espetáculo": "é preciso escrever para ser, além de ser para escrever" (SIBILIA, 2008, p. 33), e prossegue:

As escritas de si constituem objetos privilegiados quando se trata de compreender a constituição do sujeito na linguagem (ou nas linguagens) e a estruturação da própria vida como um relato - seja escrito, audiovisual ou multimídia. As novas versões dos gêneros auto-referentes que desembocam no insólito fenômeno de exibição da intimidade dizem muito sobre as configurações atuais dessas delicadas entidades: o eu e a vida, sempre fluidas e dificilmente apreensíveis, embora cada vez mais enaltecidas, veneradas e espetacularizadas (SIBILIA, 2008, p. 33-34).

Se antes, porém, os autobiografados eram personalidades ilustres que atraíam a curiosidade dos biógrafos e leitores, agora são as pessoas comuns quem expõem sua intimidade numa esfera em que as distinções modernas entre público e privado deixam de produzir efeito, simultaneamente a um movimento de declínio da cultura letrada em função da hegemonia de uma cultura visual. Essa cultura visual, presente nas telas dos blogs que apresentam materiais de 
múltiplas textualidades hipermidiatizados em narrativas fluidas que tentam dar conta de uma autoperformance de si nessa página-espetáculo, é marcada por um forte acento de oralidade. Os relatos, como atesta Sibilia, trazem a marca de uma cotidianidade num tom coloquial que incorpora, inclusive, uma transcrição literal da fonética, criando uma linguagem própria nesses registros virtuais.

A proliferação dos relatos autobiográficos na internet nos remete à prática de escrever os diários que, antigamente, eram preservados, tantas vezes, por um cadeado que negava ao outro o acesso às confissões da intimidade. Neste sentido, a atual espetacularização da privacidade denota uma mudança radical do exercício da interioridade, fazendo-nos crer que "o lado interior" só ganha dimensão simbólica na contemporaneidade a partir de sua visibilidade espetacularizada.

O fato de os novos diários íntimos serem publicados na internet não é um detalhe menor, pois o principal objetivo de tais estilizações do eu consiste precisamente em conquistar visibilidade. Em perfeita sintonia, aliás, com outross fenômenos contemporâneos que se propõem a escancarar a minúcia mais privada de todas as vidas ou de uma vida qualquer: dos reality shows às revistas de celebridades, dos talk shows na televisão à proliferação de documentários em primeira pessoa, do sucesso das biografias no mercado editorial e no cinema à crescente importância da imagem cotidiana nos políticos e em outras figuras famosas (SIBILIA, 2008, p. 75).

Tais narrativas, construindo intimidade serializada aos olhos de um público que comenta, participa e acompanha o relato, por vezes também migram das telas do computador e ganham materialidade no volume, tal qual os romances-folhetins, dependendo do sucesso dessa recepção. O número de internautas seguidores destes blogs define o sucesso editorial destas narrativas, convertidas quase sempre em best-sellers imediatos quando publicadas por alguma editora que percebe o potencial de venda destas confissões. Assim, num diálogo frequente entre a autobiografia e a literatura de auto-ajuda, a literatura de blog converte-se em verdadeiro fenômeno de venda, ajudandonos a entender a dinâmica contemporânea que se estabelece entre literatura e mercado com o surgimento do leitor-internauta.

Neste ponto, duas questões ainda parecem exigir atenção. Uma delas, presente na demanda do testemunho em primeira pessoa, parece deslizar cons- 
tantemente entre o tom confessional do registro documental e a ainda incômoda tarefa de se assumir uma autoficção. Esta voraz defesa do registro documental (talvez mais consciente em Maria Porto do que em Bruna Surfistinha) parece alimentar uma ainda inevitável fome pelo "real" por parte dos leitores. A outra questão, subjacente à primeira, reside numa idéia de experiência que este tipo de literatura parece evocar, quando se filia a um outro tipo de nicho do mercado literário, bastante rentável, que é a literatura de autoajuda. Essa literatura precisa ser acreditada como real para que o efeito da experiência, e dos conselhos decorrentes dela, ganhe sentido junto ao público.

Com relação à primeira questão, Diana Klinger (2008) aponta que o conceito de autoficção converteu-se como algo específico da narrativa contemporânea. Essa primeira pessoa autobiográfica parece assumir uma ubiquidade, fruto daquilo que ela credita a uma espécie de cultura narcisista da sociedade midiática contemporânea, aliada, num outro registro, para além da cultura midiática, a uma "crítica filosófica do sujeito que se produziu ao longo do século XX" (KLINGER, 2008, p. 14). O que nos interessa mais particularmente de suas análises sobre os processos de autoficção contemporâneos, para situarmos Bruna Surfistinha na sua relação com Raquel Pacheco, ou vice-versa, é a ideia de que tais modelos de construção de subjetividade são marcados por uma desnaturalização do eu que marca o registro performático presente na fabulação destas narrativas.

Utilizando-se da perspectiva "genderizada" de Judith Butler para refletir sobre o que há de específico na forte presença do registro autoficcional contemporâneo, Klinger aponta a particularidade do conceito butleriano de "gêneros performativos" para afastar-se da ideia de caráter genuíno na concepção antropológica de performance por Victor Turner, por exemplo, aproximando-se do que há de artificial e de encenado nestes registros. Para Butler (2001, p. 154), "a performatividade deve ser compreendida não como um 'ato' singular ou deliberado, mas ao invés disso, como a prática reiterativa e citacional pela qual o discurso produz os efeitos que ele nomeia". Dessa forma, recusando a ideia de essência dos gêneros e desnaturalizando os processos de constituição dos sujeitos, Butler ajuda Klinger a pensar a natureza contemporânea das narrativas de autoficção: um paradoxo do final do século XX que se coloca "entre um desejo narcisista de falar de si e o reconhecimento da impossibilidade de exprimir uma 'verdade' na escrita" (KLINGER, 2008, p. 18-19). 
Essa impossibilidade de expressão da verdade não inviabiliza, porém, a nossa segunda questão lançada atrás: a ideia de experiência presente na função conselheira que estes registros geralmente apresentam. Bruna Surfistinha tem, na sua contabilidade particular como garota de programa, a chancela necessária para dar conselhos sexuais a seus leitores:

Em quase três anos fazendo programa, pelas minhas contas, acho que já fiz mais de mil programas. Na teoria pode parecer pouco. Mas na prática... E não falo isso apenas por conta dos programas, do sexo em si, mas também por ter que enfrentar todo tipo de homem: bonitos, feios, cheirosos, outros nem tanto, calmos, apressados, machões, rudes, sensíveis. Hoje posso dizer que nenhuma fantasia me assusta mais, pois já fiz e vi de tudo (SURFISTINHA, 2005, p. 136).

A escritora parece perceber que a prática sexual de Bruna Surfistinha, atestada por números, a legitima a escrever a segunda parte do livro, denominada "As histórias proibidas de Bruna Surfistinha". Aqui, a narrativa expande-se de um relato biográfico para um relato abertamente identificado com o subgênero de auto-ajuda. O próprio projeto gráfico salienta esta particularidade do texto. Este caderno do livro destaca-se pelas folhas pretas que trazem as dicas da autora, dirigidas diretamente ao leitor/leitora, a respeito de incesto, relações homossexuais, pedofilia, sexo grupal, dupla penetração, gang bang, swing, chuva dourada e chuva negra, fisting, SM, strip e demais tipos de fantasias e práticas sexuais. Ela aproveita para dar dicas de higiene, cuidados preventivos, utilização de acessórios, tudo para incentivar "as pessoas [a] não terem vergonha nem medo de realizar suas fantasias" (SURFISTINHA, 2005, p. 136). O livro termina com "Os quinze mandamentos de Bruna", cujo último, que encerra o relato, reforça a preservação do mercado que garantiu sua escalada rumo ao mundo das celebridades midiáticas: "Se tiver uma fantasia que com certeza vai assustar o outro ou fazê-lo ver você como um tarado, o melhor a fazer é procurar um profissional que o satisfaça" (SURFISTINHA, 2005, p. 168).

$O$ doce veneno do escorpião ficou quase um ano na lista dos best-sellers no Brasil, figurando em primeiro lugar durante sete semanas consecutivas. Já foi publicado em vinte idiomas e lançado em vários países da América Latina, da Europa e nos Estados Unidos (CAMPOS, 2010, p. 3). Assim como as histórias apimentadas da inglesa Belle de Jour, as de Bruna Surfistinha 
também migraram para outras mídias e produziram vários outros ecos no mercado. No final de fevereiro deste ano, foi lançada a adaptação cinematográfica da primeira obra de Bruna Surfistinha, que levou mais de dois milhões de espectadores às salas de cinema no Brasil, segundo dados da Filme B. ${ }^{4}$ Além disso, seu livro de estreia provocou o lançamento de Depois do escorpião: uma história de amor, sexo e traição, pela editora Seoman, de autoria de Samantha Moraes. No livro a escritora, que também prestou um depoimento a um ghost writer, ${ }^{5}$ conta como seu marido acabou se casando com Bruna Surfistinha depois de tê-la conhecido como cliente. ${ }^{6}$ Assumindo um papel de "a traída da história", Moraes vem a público "lavar a roupa suja" e expor, no circuito das mídias, sua experiência privada. ${ }^{7}$ Em tom de auto-ajuda, o livro em resposta a' $O$ doce veneno do escorpião também termina com uma lista de 10 conselhos aos leitores/leitoras: "Dicas práticas para enfrentar e superar a síndrome de abandono".

Assim, inserindo-se num circuito midiático que transcende o mercado editorial, Bruna Surfistinha e Samantha Moraes, para além das críticas ancoradas nos critérios tradicionais de valor literário, introduzem uma interessante discussão sobre as fronteiras entre público e privado na cultura contemporânea, sobre o registro de uma intimidade inventada no interior da sociedade do

4. Disponível em: <http://www.filmeb.com.br/portal/html/portal.php>. Agradecemos aqui as informações da Filme B encaminhadas por Lia Bahia.

5. Índigo, ghost writer de Depois do escorpião, escreve, num depoimento que abre o livro de Moraes, a respeito da encomenda que recebeu: "Escrevo ficção. Para escrever algo naquela linha, teria de viver uma história daquelas. Não era o caso... (...) segui meu rumo, ruminando sobre as pesssoas que encontram na própria vida a matéria-prima para seus escritos. (...) Então ele [o editor] começou a me contar sobre quem era Samantha Moraes. Não foi preciso dizer muito para perceber que sim, ali tinha uma história. Eu acabava de ganhar uma vida para narrar!" (MORAES, 2006, p. 3)

6. Assim como $O$ doce veneno do escorpião, o livro de Samantha Moraes também vai ter uma versão cinematográfica a ser dirigida pelo cineasta Bruno Azevedo.

7. Seu depoimento de "mulher traída" não se restringiu ao relato do livro, mas também a vários programas de TV dedicados à exposição da privacidade de maneira sensacionalista, com participação do público em auditório. O diálogo entre os livros de Bruna Surfistinha e de Samantha Moraes, trazendo ao mercado editorial experiências da vida privada, não é fato isolado na esfera da cultura popular. Mary del Priore (2006, p. 279) nos lembra o já clássico bate-boca entre Dalva e Herivelto, expondo as brigas de uma separação problemática, que marcou o cenário da música popular no início da década de 1950: "A separação de Herivelto Martins e Dalva de Oliveira, por exemplo, prodigalizou um fogo cruzado entre dois gigantes da cultura popular, que tinham desfeito uma união antes apaixonada. Foi um vaivém de músicas e de acusações". 
espetáculo e sobre a produção de subcelebridades que alimenta o imaginário da cultura de massa.

\section{Referências bibliográficas}

BUTLER, Judith. Corpos que pesam: sobre os limites discursivos do "sexo". In LOURO, Guacira Lopes (Org.). O corpo educado: pedagogias da sexualidade. Trad. Tomaz Tadeu da Silva. Belo Horizonte: Autêntica, 2001, p. 151-172.

CAMPOS, Cynthia de Lima. O dia em que Raquel Pacheco saiu do anonimato: Bruna Surfistinha e a morte do autor. Ícone (online), v. 12, Recife, p. 2, 2010.

KLINGER, Diana Irene. A escrita de si como performance. Revista Brasileira de Literatura Comparada, v. 12, p. 11-30, 2008.

MEYER, Marlyse. Folhetim: uma história. São Paulo: Companhia das Letras, 1996.

MORAES, Samantha. Depois do escorpião: uma história de amor, sexo e traição. São Paulo: Seoman, 2006.

PRIORE, Mary del. História do amor no Brasil. São Paulo: Contexto, 2005.

SIBILIA, Paula. O show do eu: a intimidade como espetáculo. Rio de Janeiro: Nova Fronteira, 2008.

SINGER, Ben. Modernidade, hiperestímulo e o início do sensacionalismo. In CHARNEY, Leo e SCHWARTZ, Vanessa (orgs). O cinema e a invenção da vida moderna. Trad. Regina Thompson. São Paulo: Cosac \& Naify, 2001, p. 95-126.

SURFISTINHA, Bruna. O doce veneno do escorpião. São Paulo: Panda Books, 2005.

Recebido em 03 de maio e aprovado em 10 de junho de 2011. 